\title{
Pelvic floor muscle training for overactive bladder symptoms - A prospective study
}

\author{
Fátima Fitz ${ }^{1 *}$, Marair Sartorl ${ }^{2}$, Manoel João Girão², Rodrigo Castro ${ }^{2}$ \\ ${ }^{1}$ PT, PhD. Department of Gynecology, Universidade Federal de São Paulo (UNIFESP), São Paulo, SP, Brazil \\ ${ }^{2} \mathrm{MD}$, PhD. Department of Gynecology, UNIFESP, São Paulo, SP, Brazil
}

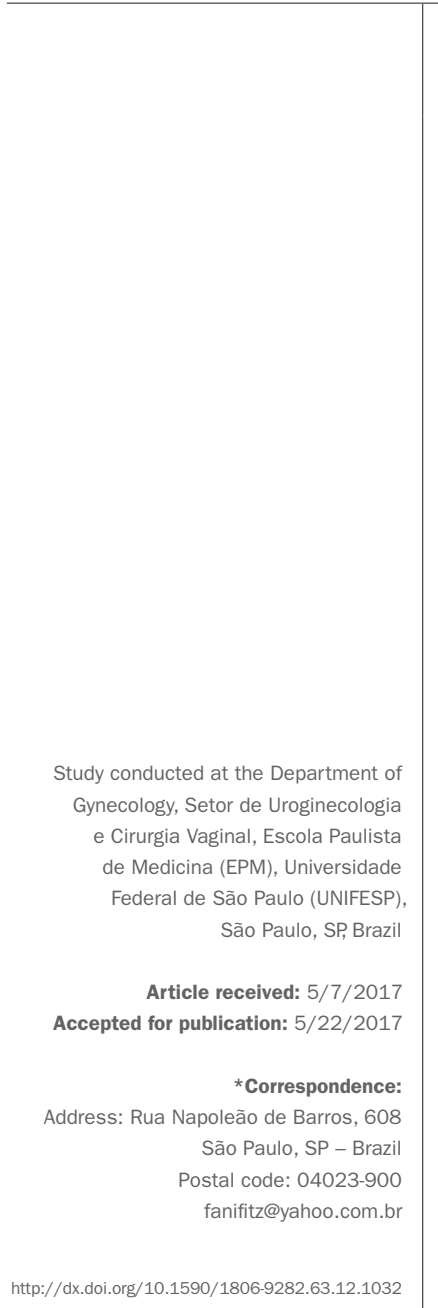

\section{SUMmARY}

Introduction: Pelvic floor muscle training (PFMT) involves the contraction of the puborectal, anal sphincter and external urethral muscles, inhibiting the detrusor contraction, what justify its use in the treatment of overactive bladder (OAB) symptoms.

Objective: To verify the effects of isolated PFMT on the symptoms of OAB.

Method: Prospective clinical trial with 27 women with mixed urinary incontinence (MUI), with predominance of OAB symptoms and loss $\geq 2 \mathrm{~g}$ in the pad test. It was evaluated: pelvic floor muscles (PFMs) function (digital palpation and manometry); urinary symptoms (nocturia, frequency and urinary loss); degree of discomfort of OAB symptoms; and quality of life (Incontinence Quality-ofLife Questionnaire [I-QoL]). The PFMT program consisted of 24 outpatient sessions (2x/week + home PFMT). The Mann-Whitney and Wilcoxon tests (with a significance level of 5\%) were used to analyse the data.

Results: There was a significant improvement of the urinary symptoms to the pad test $(5.8 \pm 9.7, \mathrm{p}<0.001)$, urinary loss $(0.7 \pm 1.1, \mathrm{p}=0.005)$ and nocturia $(0.8 \pm 0.9$, $\mathrm{p}=0.011)$. Reduction in the degree of discomfort of urinary symptoms was observed according to OAB-V8 questionnaire (10.0 $7.7, \mathrm{p}=0.001)$. There were also significant results in PFMs function: Oxford (3.6 $\pm 0.9, \mathrm{p}=0.001)$, endurance (5.2 $\pm 1.8, \mathrm{p}<0.001)$, fast $(8.9 \pm 1.5, \mathrm{p}<0.001)$ and manometry $(26.6 \pm 15.8, \mathrm{p}=0.003)$. In addition, quality of life had a significant improvement in the three domains evaluated by I-QoL.

Conclusion: The PFMT without any additional guidelines improves the symptomatology, the function of PFMs and the quality of life of women with OAB symptoms.

Keywords: urinary incontinence, pelvic floor, physical therapy modalities.

\section{INTRODUCTION}

Overactive bladder (OAB) syndrome, also know as urgency syndrome or urgency-frequency syndrome, is a clinical diagnosis characterized by voiding urgency, with or without urgency urinary incontinence (UUI), usually accompanied by nocturia and increased voiding frequen$\mathrm{cy}$, in the absence of infectious or metabolic factors. ${ }^{1}$

$\mathrm{OAB}$ symptoms compromise quality of life, causing social isolation, a decline in productivity, shame, frustration, anxiety and low self-esteem. ${ }^{2}$ Symptoms include increased voiding frequency, present in approximately
$85 \%$ of patients, followed by urgency, present in $54 \%{ }^{3}$ UUI, in turn, is present in one third of the patients. ${ }^{4} \mathrm{En}$ uresis, nocturia and urinary leakage due to stress incontinence are also reported. ${ }^{5}$

The main therapeutic modalities are conservative therapies, such as pharmacological treatment and behavioral therapy. Behavioral therapy includes the association of various resources, such as: educational program; changes in lifestyle; bladder training and urge suppression strategies; pelvic floor muscle training (PFMT); electro-stimulation; and programmed urination. ${ }^{6-8}$ 
The effects of behavioral therapy in the treatment of $\mathrm{OAB}$ symptoms are extensively studied and their efficacy, proven. ${ }^{9}$ The literature investigating the effects of PFMT on OAB symptoms, without the association of other techniques, is scarce. The justification for using PFMT is that PFM contraction inhibits detrusor contraction, thus improving the symptoms of detrusor overactivity..$^{10}$ Accordingly, our main question is: Does PFMT alone result in improved symptoms of detrusor overactivity? Secondarily, we assessed the PFM function and the quality of life of women with $\mathrm{OAB}$ symptoms.

\section{Method}

\section{Study design and population}

This is a prospective clinical trial conducted from March 2011 to September 2013. The study was developed at the Urogynecology and Vaginal Surgery Unit of the General Gynecology Division, Department of Gynecology, at Universidade Federal de São Paulo (Unifesp). The Unifesp Research Ethics Committee granted approval for the study (protocol number CEP 1981/10). All participants signed the Voluntary Informed Consent Form, drafted in accordance with Resolution No. 196/96 of the National Health Council.

We included women with a history of mixed urinary incontinence (MUI) who reported OAB symptoms, with urinary leakage $\geq 2 \mathrm{~g}$ on the standardized volume pad test during medical appointment. Exclusion criteria were chronic-degenerative diseases; greater than grade II pelvic organ prolapse; urinary tract infection; neurological or psychiatric disease; present or past use of anticholinergics and tricyclic antidepressants during up to 6 months; or previous PFM training.

Once the participants were included, we initially collected their socio-demographic (age) and clinical (body mass index and urinary leakage time) information, as well as obstetric history (parity, vaginal delivery). Subsequently, the participating women were referred to a physiotherapist specialized in urogynecology, who assessed PFM function, urinary symptoms and quality of life.

\section{PFM function assessment}

PFM function was assessed by digital palpation, according to the PERFECT scheme. The Oxford scale was used for quantifying muscle strength. It assesses muscle strength from 0 to 5. Muscle endurance and rapid contractions were also assessed by means of the PERFECT system, an acronym meaning: Power $(\mathrm{P})$, Endurance $(\mathrm{E})$ and Fast $(\mathrm{F})$, i.e. number of fast contractions. ${ }^{11}$

After digital examination, the maximum voluntary contraction (MVC) pressure of the pelvic floor muscles was assessed using a Peritron manometer (Cardio Design ${ }^{\mathrm{TM}}$, Victoria, Austrália). It is a conical vaginal catheter that is connected to a hand-held microprocessor with a latex tube, which allows pressure readings to be transmitted in centimeters of water $\left(\mathrm{cmH}_{2} \mathrm{O}\right)$ when the catheter is compressed due to external pressure. The catheter was covered with a sterile condom and inserted into the vaginal canal until the entire length of the compressible part of the device was above the level of the hymenal annulus. The baseline pressure reading was recorded, and the catheter was then inflated to $100 \mathrm{cmH}_{2} \mathrm{O}$ and the device was then set to zero. Participants were requested to hold three consecutive MVCs, with a 10-second interval between each contraction ${ }^{12}$ and the best of three was recorded. ${ }^{13}$

\section{Assessment of urinary symptoms}

$\mathrm{OAB}$ syndrome was assessed based on the Overactive Bladder Questionnaire (OAB-V8). This scale includes items on urgency, incontinence, nocturia and voiding frequency, as defined by the International Continence Society (ICS), referring to the previous four weeks. The final score is the sum of the partial scores obtained for each of the eight questions, ranging from 0 to 40 . Patients with a final score of eight or more are considered as having OAB symptoms. ${ }^{14}$

Patients were also instructed to keep a voiding diary for seven days. In this diary, diurnal urinary frequency, nocturia and urinary leakage in situations of stress (coughing, sneezing, laughing, squatting, weight lifting, walking, and running) were recorded. ${ }^{15}$

We also conducted a standardized bladder volume pad test in order to analyze the severity of urinary incontinence. Firstly, the bladder was emptied with a catheter, and $250 \mathrm{~mL}$ of injection water were then infused. The participants used pre-weighted sanitary napkins and did the following physical activities: ten jumps, ten squats, ten coughs, climb and descend five flights of stairs ten times, walking for 15 minutes and washing hands for one minute. After the activities were completed, the pads were weighed again to determine the amount of leakage. ${ }^{16}$

\section{Assessment of quality of life}

The impact of $O A B$ syndrome symptoms on quality of life was assessed based on the Incontinence Quality-of-Life (I-QoL) Questionnaire. The I-QoL Questionnaire consists of 22 questions that assess the limitations on human behavior, the psychosocial impact and social constraint brought about by urinary incontinence. Responses are given on a scale ranging from 1 to 5 points and the final scores are then summed up and converted into percentages. The higher the percentage, the better the quality of life. ${ }^{17}$ 


\section{PFM training protocol}

The treatment consisted of outpatient sessions conducted under the supervision of the physiotherapist (24 outpatient sessions of 40 minutes each) and home training for 12 weeks.

A program consisting of three sets of ten repetitions per day was prescribed. The treatment protocol was personalized and based on the initial evaluation as assessed by PERFECT. We instructed our patients to contract and hold the contraction for some seconds (the time corresponds to the reading obtained during the initial assessment - from 1 to 10 seconds), which were then followed by fast contractions (calculated in the same way). One series of exercises consisted of ten repetitions of each movement (endurance + rest + fast contractions). For example, if 6 seconds of muscle endurance and three fast muscle contractions were observed in the PERFECT system, we instructed our patients to hold maximum voluntary contraction for 6 seconds, and twice as long the second time (12 seconds), finally followed by three rapid contractions (Figure 1). PFM function assessment by the PERFECT system took place monthly for training adjustments and progression. ${ }^{18}$ No additional resources were addressed for treating $O A B$ syndrome symptoms in addition to PFMT.

We instructed our patients to use the same protocol they learned during the outpatient sessions daily but at home, in the supine (first month), seated (second month) and orthostatic (third month) positions (Figure 2).

\section{Adherence to the PFM training program}

To monitor adherence to home exercises, patients completed an exercise diary. Adherence to the training proto- col was based on the daily PFM training records performed by the patients (three sets of daily exercises). We instructed patients to record exercises only when they actually practiced them. Adherence was expressed as the average of series of exercises patients did monthly during the treatment period. ${ }^{19}$ Outpatient attendance at sessions was monitored by the physiotherapist accompanying the patients during treatment and expressed as an average at the end of the three-month treatment.

For the statistical analysis, we used the SPSS software version 22.0. For analyzing demographic data, clinical traits and adherence to the exercises, we used the MannWhitney test. In order to analyze possible differences before and after treatment, we used the Wilcoxon test with a significance level of $5 \%$.

\section{Results}

Twenty-seven (27) patients were included in the period between March 2011 and September 2013. Seven women did not complete the treatment (35\% dropout rate). Reasons reported for dropout were: two patients reported difficulties in obtaining release from work; three due to family reasons; and another two due to prioritizing the treatment of other health conditions. Demographic and clinical traits are described in Table 1.

In comparing the urinary symptoms between the initial and final assessments conducted during the treatment, we observed significant improvement in the severity of UI as assessed in the pad test; in urinary leakage and nocturia, as evaluated with the voiding diary; in $\mathrm{OAB}$ symptoms as assessed by the OAB-V8 questionnaire; and in the three domains of quality of life assessment as evaluated by the I-QoL questionnaire (Table 2).

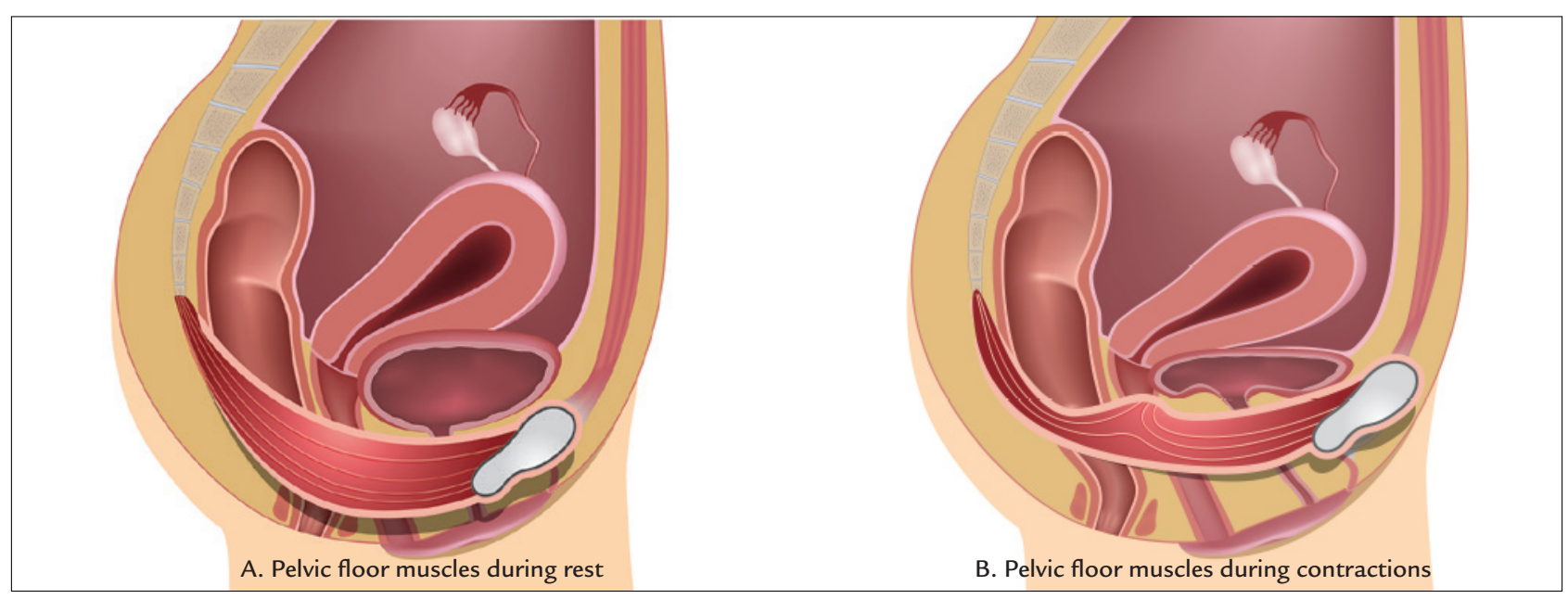

FIGURE 1 Illustration of pelvic floor muscles at rest (A) and during contraction (B). 


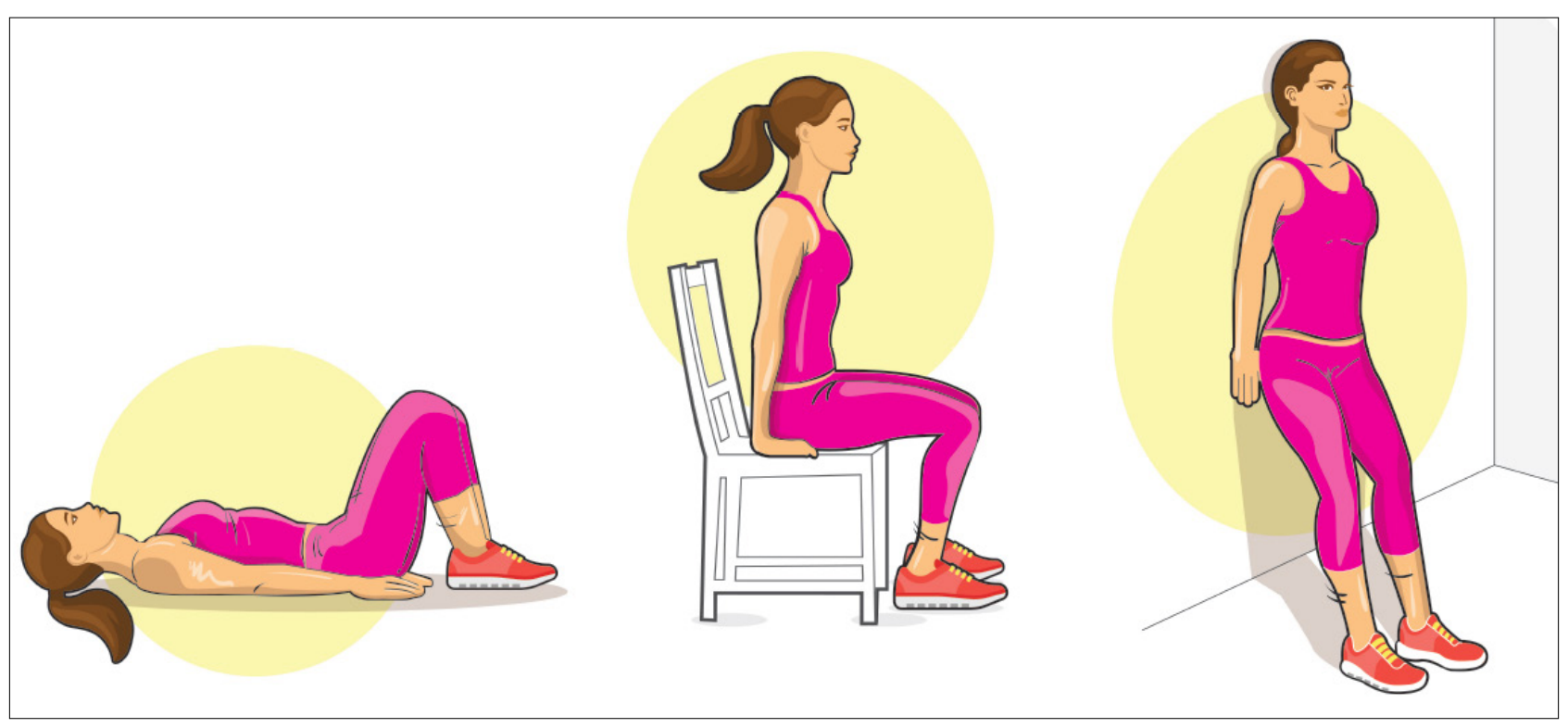

FIGURE 2 Illustration of patient positioning for performing exercises at home.

\section{TABLE 1 Clinical and demographic characteristics of the patients.}

\begin{tabular}{ll} 
Variables $(\mathbf{n}=\mathbf{2 0})$ & Mean (minimum-maximum) \\
\hline Age $($ years $)$ & $59.9(41-77)$ \\
\hline BMI $\left(\mathrm{kg} / \mathrm{m}^{2}\right)$ & $27.4(21-38)$ \\
\hline Duration of symptoms (months) & $128.4(12-420)$ \\
\hline Pregnancies $(\mathrm{n})$ & $5.1(2-16)$ \\
\hline Parity $(\mathrm{n})$ & $3.5(0-12)$ \\
\hline
\end{tabular}

Mann-Whitney; $\mathrm{n}$ : sample size; BMI: body mass index.

TABLE 2 Assessment of urinary symptoms (pad test, voiding diary, OAB-V8) and quality of life before and after treatment.

\begin{tabular}{llll} 
Variables $(\mathbf{n}=\mathbf{2 0})$ & Baseline $($ mean $\pm \mathbf{S D})$ & Final $(\mathbf{m e a n} \pm \mathbf{S D})$ & $\mathbf{P}$ \\
\hline Pad test $(\mathrm{g})$ & $19.5 \pm 22.2$ & $5.8 \pm 9.7$ & $<0.001^{*}$ \\
\hline Urinary leakage & $2.1 \pm 1.6$ & $0.7 \pm 1.1$ & $0.005^{*}$ \\
\hline Frequency & $7.4 \pm 2.8$ & $6.7 \pm 2.2$ & 0.360 \\
\hline Nocturia & $1.6 \pm 1.6$ & $0.8 \pm 0.9$ & $0.011^{*}$ \\
\hline OAB-V8 & $21.9 \pm 7.2$ & $10.0 \pm 7.7$ & $<0.001^{*}$ \\
\hline Limitations on human behavior & $103.2 \pm 28.8$ & $135.5 \pm 21.3$ & $0.001^{*}$ \\
\hline Psychosocial impact & $140.5 \pm 36.8$ & $170.5 \pm 29.2$ & $0.005^{*}$ \\
\hline Embarrasment and social constraint & $44.5 \pm 30.7$ & $59.7 \pm 28.3$ & $0.024^{*}$ \\
\hline
\end{tabular}

Wilcoxon*; SD: standard deviation; n: sample size; g: grams; OAB-V8: Overactive Bladder Questionnaire; I-QoL: Incontinence Quality-of-Life Questionnaire.

During PFM assessment, we observed improvement in muscle function when comparing the initial and final assessments conducted during the treatment, evaluated with the PERFECT system and the manometer (Table 3).

The mean outpatient attendance during outpatient PFMT was $18.4 \pm 4.6$ sessions. Adherence to in-home ex- ercises (series of exercises completed) was: $78.3 \pm 15.5$ (30$82)$ in the first month; $74.6 \pm 16.3$ (24-82) in the second month; and 76.2 \pm 16.0 (24-82) in the third month.

\section{Discussion}

PFMT is among the types of conservative treatment for urinary symptoms. This is a low-cost, first-line treatment 
TABLE 3 Assessment of the function of pelvic floor muscles (manometry and PERFECT) before and after treatment.

\begin{tabular}{llll} 
Variables $(\mathbf{n}=\mathbf{2 0})$ & Baseline $($ mean \pm SD $)$ & Final $(\mathbf{m e a n} \pm \mathbf{S D})$ & $\mathbf{P}$ \\
\hline $\mathrm{MVC}\left(\mathrm{cmH}_{2} \mathrm{O}\right)$ & $19.7 \pm 12.2$ & $26.6 \pm 15.8$ & $0.003^{*}$ \\
\hline Oxford & $2.6 \pm 1.1$ & $3.6 \pm 0.9$ & $0.001^{*}$ \\
\hline Endurance $(\mathrm{s})$ & $2.7 \pm 1.2$ & $5.2 \pm 1.8$ & $<0.001^{*}$ \\
\hline Fast & $5.3 \pm 2.4$ & $8.9 \pm 1.5$ & $<0.001^{*}$ \\
\hline
\end{tabular}

Wilcoxon; SD: standard deviation; s: seconds; n: sample size; MVC: maximum voluntary contraction.

for women with stress urinary incontinence (SUI). ${ }^{8}$ Its success rates range from 60 to $75 \% .^{15,20}$

In addressing $O A B$ symptoms, behavioral therapy programs appear as first-rate treatments. These programs include the association of techniques that aim at minimizing or even eliminating the symptoms displayed by the patient. Behavioral therapy programs include: educational program, changes in lifestyle, bladder training and urge suppression strategies, encouragement and positive reinforcement, programmed urination, PFMT, PFMT with biofeedback (BF) and PFMT with electrostimulation. ${ }^{6}$ In our study, we proposed to use only PFMT for the treatment of OAB symptoms. We observed a significant improvement in PFM function, urinary symptoms and quality of life after 12 weeks of outpatient and in-home training.

Studies published in the literature that make use of PFMT alone for OAB symptoms are scarce. In our study, we observed an improvement in muscle function as measured by digital palpation $(\mathrm{p}<0.001)$ and manometry $(p<0.001)$. Wang et al. used the isolated PFMT, training with $\mathrm{BF}$, and coupled with electrostimulation without combining other resources to suppress urgency and urge incontinence. Improvement in PFM function was found across all three groups, with greater relevance in the BF group. The increase in vaginal contraction pressure was $105 \%$ in the BF group; $78.9 \%$ in the PFMT group; and only $12.6 \%$ in the electrostimulation group. ${ }^{21} \mathrm{BF}$ is an adjuvant to PFMT and allows patients to observe PFM contractions during exercise, thereby improving exercise performance and treatment motivation, ${ }^{22-24}$ which may justify a significant improvement in PFM function.

However, Wang et al. ${ }^{21}$ do not consider muscle strength the best indicator when assessing OAB symptoms. Treatment of overactive bladder symptoms should be evaluated by its effectiveness in reducing urinary symptoms and its impact on quality of life.

In our study, we observed an improvement in urinary leakage as assessed by pad test $(\mathrm{p}<0.001)$, voiding diary $(\mathrm{p}=0.005)$, nocturia $(\mathrm{p}=0.011)$ and degree of discomfort caused by urinary symptoms as assessed by the OAB-V8 questionnaire ( $p$ <.001). In assessing quality of life, we also observed positive results in the three domains evaluated by the I-QoL questionnaire. There was no significant reduction in urinary frequency, given that initial values were within normal standards, according to the International Urogynecological Association (IUGA)/International Continence Society (ICS). ${ }^{1}$

Wang et al. ${ }^{21}$ found urinary symptom reduction rates of about $51 \%$ in the electrostimulation group, $50 \%$ in the isolated PFMT group and 38\% in the PFMT group with $\mathrm{BF}$. The authors found electrostimulation to be superior to the other groups. Electrostimulation inhibits detrusor activity by directly stimulating the pudendal nerve. ${ }^{25}$ Burgio et al. ${ }^{26}$ observed incontinence reduction of about $80 \%$ in women with urge incontinence by using PFMT with BF.

In a study with the specific objective of evaluating and comparing the effects of oxybutynin, electrostimulation and perineal exercises in the treatment of detrusor overactivity, the urge incontinence decreased in all three groups $(\mathrm{p}<0.05)$ following treatment as assessed by the voiding diary. Urgency disappeared in about $63 \%$ of patients in the oxybutynin group; in $52 \%$ of patients in the electrostimulation group; and in $57 \%$ of patients in the perineal exercises group. The results were similar between the groups $(\mathrm{p}=0.754)$. In the subjective evaluation, the percentage of women who were satisfied after treatment was $77 \%, 52 \%$ and $76 \%$, respectively, in the oxybutynin, electrostimulation and perineal exercise groups, with no significant differences between them $(\mathrm{p}=0.142){ }^{5}$

The benefits of short- and long-term physiotherapeutic treatment programs depend on patient adherence. ${ }^{27}$ In our study, we observed an outpatient attendance of $75 \%$ and a mean in-home adherence during the 3 month treatment of $80 \%$.

The results from these studies should be compared with caution, as there are differences in the inclusion criteria and disease definitions across them, as well as specific criteria for evaluating cure and improvement in symptoms. Most studies combined treatments, which makes it difficult to understand how each of the resources can act individually. In our sample, the patients did not receive any information on behavioral orientation. 
There is insufficient evidence to support PFMT in treating OAB symptoms, since it is unclear how PFM contraction can inhibit detrusor contractions. PFMT involves the contraction of the puborectalis muscles, as well as the anal and external urethral sphincters. Studies have shown that contraction of these muscles leads to suppression of detrusor contraction. ${ }^{28,29}$ The studies published in the literature that use PFMT for OAB are scarce, and most of them rely on the association of different treatment modalities.

Our study is a prospective trial that shows benefits of isolated PFMT in improving urinary leakage symptoms, nocturia, quality of life and PFM function. Nonetheless, randomized controlled trials are needed to further demonstrate and understand how women with OAB symptoms can benefit from PFMT.

\section{Conclusion}

Our results suggest that PFMT with no additional guidelines can improve urinary leakage, nocturia, PFM function and quality of life in women with OAB symptoms. Still, randomized controlled trials using PFMT alone are required in order to better demonstrate and understand how it can act on OAB symptoms.

\section{Resumo}

Treinamento dos músculos do assoalho pélvico nos sintomas da bexiga hiperativa - Um estudo prospectivo

Introdução: $\mathrm{O}$ treinamento dos músculos do assoalho pélvico (TMAP) envolve a contração dos músculos puborretal, esfíncteres anal e uretral externo, inibindo a contração do detrusor, o que justifica sua utilização no tratamento dos sintomas da bexiga hiperativa (BH).

Objetivo: Verificar os efeitos do TMAP isolado sobre a sintomatologia da BH.

Método: Ensaio clínico prospectivo com 27 mulheres com incontinência urinária mista (IUM), com predomínio de sintomas de $\mathrm{BH}$ e perda $\geq 2 \mathrm{~g}$ no pad test. Avaliaram-se: função dos músculos do assoalho pélvico (MAP) (palpação digital e manometria); sintomas urinários (noctúria, frequência e perda urinária); grau de incômodo dos sintomas de BH (Overactive Bladder Questionnaire [OAB-V8]); e qualidade de vida (Incontinence Quality-of-Life Questionnaire [I-QoL]). O programa de TMAP consistiu em 24 sessões ambulatoriais (2x/semana + TMAP domiciliar). Os testes de Mann-Whitney e Wilcoxon (com nível de significância de 5\%) foram utilizados para analisar os dados.

Resultados: Observou-se melhora significativa dos sintomas urinários ao pad test $(5,8 \pm 9,7 ; \mathrm{p}<0,001)$; ao diário miccional (perda urinária $[0,7 \pm 1,1 ; \mathrm{p}=0,005]$ e noctúria $[0,8 \pm 0,9 ; \mathrm{p}=0,011])$. Foram observados redução do grau de incômodo dos sintomas urinários conforme questionário OAB-V8 $(10,0 \pm 7,7 ; \mathrm{p}=0,001)$ e significativos resultados na função dos MAP: Oxford $(3,6 \pm 0,9 ; \mathrm{p}=0,001)$, Endurance $(5,2 \pm 1,8 ; \mathrm{p}<0,001)$, Fast $(8,9 \pm 1,5 ; \mathrm{p}<0,001) \mathrm{e}$ manometria $(26,6 \pm 15,8 ; \mathrm{p}=0,003)$. No mais, a qualidade de vida teve significativa melhora nos três domínios avaliados pelo I-QoL.

Conclusão: O TMAP sem quaisquer orientações adicionais melhora a sintomatologia, a função dos MAP e a qualidade de vida de mulheres com sintomas de BH.

Palavras-chave: incontinência urinária, diafragma da pelve, modalidades de fisioterapia.

\section{References}

1. Haylen BT, Ridder D, Freeman RM, Swift SE, Berghmans B, Lee J, et al. An International Urogynecological Association (IUGA)/International Continence Society (ICS) joint report on the terminology for female pelvic floor dysfunction. Int Urogynecol J. 2010; 21(1):5-26.

2. Sand PK, Appell R. Disruptive effects of overactive bladder and urge urinary incontinence in younger women. Am J Med. 2006; 119(3 Suppl 1):16-23.

3. Milsom I, Abrams P, Cardozo L, Roberts RG, Thüroff J, Wein AJ. How widespread are the symptoms of an overactive bladder and how are they managed? A population-based prevalence study. BJU Int. 2001; 87(9):760-6.

4. Wein AJ, Rackley RR. Overactive bladder: a better understanding of pathophysiology, diagnosis and management. J Urol. 2006; 175(3 Pt 2):S5-10.

5. Arruda RM, Sousa GO, Castro RA, Sartori MGF, Baracat EC, Girão MJBC. Hiperatividade do detrusor: comparação entre oxibutinina, eletroestimulação funcional do assoalho pélvico e exercícios perineais. Estudo randomizado. Rev Bras Ginecol Obstet. 2007; 29(9):452-8.

6. Newman DK, Wein AJ. Office-based behavioral therapy for management of incontinence and other pelvic disorders. Urol Clin North Am. 2013; 40(4):613-35.

7. Kaya S, Akbayrak T, Gursen C, Beksac S. Short-term effect of adding pelvic floor muscle training to bladder training for female urinary incontinence: a randomized controlled trial. Int Urogynecol J. 2015; 26(2):285-93.

8. Hay-Smith EJ, Herderschee R, Dumoulin C, Herbison PG. Comparisons of approaches to pelvic floor muscle training for urinary incontinence in women. Cochrane Database Syst Rev. 2011; (12):CD009508.

9. Ayeleke RO, Hay-Smith EJ, Omar MI. Pelvic floor muscle training added to another active treatment versus the same active treatment alone for urinary incontinence in women. Cochrane Database Syst Rev. 2013; (11):CD010551.

10. Gunnarsson M, Teleman P, Mattiasson A, Lidfeldt J, Nerbrand C, Samsioe G. Effects of pelvic floor exercises in middle aged women with a history of naïve urinary incontinence: a population based study. Eur Urol. 2002; 41(5):556-61.

11. Laycock J, Jerwood D. Pelvic floor muscle assessment: the PERFECT scheme. Physiotherapy. 2001; 87(12):631-42.

12. Bø K, Finckenhagen HB. Vaginal palpation of pelvic floor muscle strength: inter-test reproducibility and comparison between palpation and vaginal squeeze pressure. Acta Obstet Gynecol Scand. 2001; 80(10):883-7.

13. Grape HH, Dedering A, Jonasson AF. Retest reliability of surface electromyography on the pelvic floor muscles. Neurourol Urodyn. 2009; 28(5):395-9.

14. Acquadro C, Kopp Z, Coyne KS, Corcos J, Tubaro A, Choo MS, et al. Translating overactive bladder questionnaires in 14 languages. Urology. 2006; 67(3):536-40

15. Castro RA, Arruda RM, Zanetti MR, Santos PD, Sartori MG, Girão MJ. Singleblind, randomized, controlled trial of pelvic floor muscle training, electrical stimulation, vaginal cones, and no active treatment in the management of stress urinary incontinence. Clinics (Sao Paulo). 2008; 63(4):465-72. 
16. Lose G, Rosenkilde P, Gammelgaard J, Schroeder T. Pad-weighing test performed with standardized bladder volume. Urology. 1988; 32(1):78-80.

17. Souza CC, Rodrigues AM, Ferreira CE, Fonseca ES, di Bella ZI, Girão MJ, et al. Portuguese validation of the Urinary Incontinence-Specific Quality-ofLife Instrument: I-QOL. Int Urogynecol J Pelvic Floor Dysfunct. 2009; 20(10):1183-9.

18. Konstantinidou E, Apostolidis A, Kondelidis N, Tsimtsiou Z1, Hatzichristou D1, Ioannides E. Short-term efficacy of group pelvic floor training under intensive supervision versus unsupervised home training for female stress urinary incontinence: a randomized pilot study. Neurourol Urodyn. 2007; 26:(4):486-91.

19. Felicíssimo MF, Carneiro MM, Salene CS, Pinto RZ, Fonseca AM, SilvaFilho AL. Intensive supervised versus unsupervised pelvic floor muscle training for the treatment of stress urinary incontinence: a randomized comparative trial. Int Urogynecol J. 2010; 21(7):835-40.

20. $\mathrm{B} ø \mathrm{~K}$, Talseth $\mathrm{T}$, Holme I. Single blind, randomised controlled trial of pelvic floor exercises, electrical stimulation, vaginal cones, and no treatment in management of genuine stress incontinence in women. BMJ. 1999; 318(7182):487-93

21. Wang AC, Wang YY, Chen MC. Single-blind, randomized trial of pelvic floor muscle training, biofeedback-assisted pelvic floor muscle training, and electrical stimulation in the management of overactive bladder. Urology. 2004; 63(1):61-6.
22. Fitz FF, Resende AP, Stüpp L, Sartori MG, Girão MJ, Castro RA. Biofeedback for the treatment of female pelvic floor muscle dysfunction: a systematic review and meta-analysis. Int Urogynecol J. 2012; 23(11):1495-516.

23. $\mathrm{B} \varnothing \mathrm{K}$, Herbert $\mathrm{R}$. There is not yet strong evidence that exercises regimens other than pelvic floor muscle training can reduce stress urinary incontinence in women: a systematic review. J Physiother. 2013; 59(3):159-68.

24. Glavind K, Nøhr S, Walter S. Pelvic floor training using biofeedback for muscle awareness in the treatment of stress urinary incontinence: preliminary results. Int Urgoynecol J. 1992; 3(4):288-91.

25. Fall M, Lindstrom S. Functional electrical stimulation: physiological basis and clinical principles. Int Urogynecol J. 1994; 5(5):296-304.

26. Burgio KL, Locher JL, Goode PS, Hardin JM, McDowell BJ, Dombrowski M, et al. Behavioral vs drug treatment for urge urinary incontinence in older women: a randomized controlled trial. JAMA. 1998; 280(23):1995-2000.

27. Chen SY, Tzeng YL. Path analysis for adherence to pelvic floor muscle exercise among women with urinary incontinence. J Nurs Res. 2009; 17(2):83-92.

28. Shafik A, el-Sibai $O$. Rectal inhibition by inferior rectal nerve stimulation in dogs: recognition of a new reflex: the 'voluntary anorectal inhibition reflex'. Eur J Gastroenterol Hepatol. 2001; 13(4):413-8.

29. Shafik A. A study on the continence mechanism of the external urethral sphincter with identification of the voluntary urinary inhibition reflex. J Urol. 1999; 162(6):1967-71. 